RESEARCH REPORT

\title{
Breast cancer survival in South Asian women in England and Wales
}

\author{
Sabya Farooq, Michel P Coleman
}

J Epidemiol Community Health 2005;59:402-406. doi: 10.1136/jech.2004.030965

See end of article for authors' affiliations .....................

Correspondence to: Dr S Faroog, Noncommunicable Disease Epidemiology Unit, London School of Hygiene and Tropical Medicine, Keppel Street, London WCIE 7HT, UK; sabya.farooq@|shtm. ac.uk

Accepted for publication 9 November 2004

\begin{abstract}
Study objectives: To estimate ethnic and socioeconomic differences in breast cancer incidence and survival between South Asians and non-South Asians in England and Wales, and to provide a baseline for surveillance of cancer survival in South Asians, the largest ethnic minority.

Setting: 115712 women diagnosed with first primary invasive breast cancer in England and Wales during 1986-90 and followed up to 1995 .

Methods/design: Ethnic group was ascribed by a computer algorithm on the basis of the name. Incidence rates were derived from 1991 census population denominators for each ethnic group. One and five year relative survival rates were estimated by age, quintile of material deprivation, and ethnic group, using national mortality rates to estimate expected survival.

Main results: Age standardised incidence was 29\% lower among South Asian women (40.5 per 100000 per year) than among all other women (57.4 per 100 000). Five year age standardised relative survival was $70.3 \%(95 \% \mathrm{Cl} 65.2$ to 75.4$)$ for South Asian women and $66.7 \%$ (66.4 to 67.0) for other women. For both ethnic groups, survival was $8 \%-9 \%$ higher for women in the most affluent group than those in the most deprived group. In each deprivation category, however, survival was 3\%-8\% higher for South Asian women than other women.

Conclusions: This national study confirms that breast cancer incidence is substantially lower in South Asians than other women in England and Wales. It also provides some evidence that South Asian women diagnosed up to 1990 had higher breast cancer survival than other women in England and Wales, both overall and in each category of deprivation.
\end{abstract}

\section{METHODS}

\section{Data and patients}

Data on women with a first primary, invasive malignancy of the breast diagnosed during 1986-90 and followed up to the end of 1995 were extracted from a public use CD ROM on cancer survival in England and Wales. ${ }^{22}$ The data were originally collected by regional cancer registries and submitted to the National Cancer Registry for England and Wales at the Office for National Statistics (ONS). Of the 137664 eligible tumour records, about 15\% had been excluded because the woman's vital status was unknown when the data were extracted, or their survival was unknown: 115712 (84.1\%) women were included in the analysis. Multiple primary tumours were also excluded. An anonymised data extract of these records was linked back to names by ONS for the purpose of this analysis. The South Asian Names and Group Recognition Algorithm (SANGRA) was used to ascribe ethnicity on the basis of the names; the file was then re-anonymised before analysis. Survival was examined as a function of age at diagnosis, ethnic group, and deprivation category. Analyses were also done by region of residence at time of diagnosis, anatomical sub-site, and morphology, but results are not presented here.

Patients were assigned to a category of material deprivation using the Carstairs index, ${ }^{23}$ a small area score of material deprivation derived from census data. Quintiles of its distribution among the 109578 census enumeration districts in Great Britain were used to assign a deprivation category from 1 (most affluent) to 5 (most deprived) to each woman by linking her postcode of residence at diagnosis to the corresponding enumeration district. ${ }^{25} \mathrm{~A}$ small proportion of patients (about $1 \%$ ) could not be reliably assigned to a
Ethnicity is still not recorded on birth certificates, deat certificates, GP patient lists, or in most disease registers. 
deprivation category; they were included only in overall estimates of survival.

\section{Analysis}

South Asian ethnicity was defined, irrespective of birthplace, as an ethnic origin in peoples indigenous to India, Pakistan, or Bangladesh. SANGRA ${ }^{26}$ was used to identify South Asian women by matching their names to libraries that contained 9917 first names and 9422 surnames recognised as typically belonging to South Asians. A 1\% systematic sample of records not identified as South Asian was examined to check for false negatives.

Incidence rates were derived using 1991 national census populations for each ethnic group as denominators. ${ }^{18}$ Of the 25707284 women of all ages, 710601 (2.8\%) were of Indian, Pakistani, or Bangladeshi origin. Relative survival rates ${ }^{27-29}$ were estimated at one and five years since diagnosis, with an algorithm ${ }^{25}$ developed in Stata software (Stata Corporation, College Station, TX, 1997). using the method of Estève et al. ${ }^{30}$ The official life table, ${ }^{31}$ based on all cause mortality in all ethnic groups combined in England and Wales during the peri-censal period 1990-92, was used to adjust for background mortality. The period 1990-92 was central to the period 1986-95 covered by the study. Life tables for specific ethnic groups were unavailable and could not be constructed, because data on ethnic group are not collected at death. Deprivation specific life tables for all women from 1990-92 were used ${ }^{25}$ again in the absence of ethnic group specific life tables by deprivation.

Relative survival rates were standardised for age using the direct method. Standard weights for the age groups 15-39, $40-49,50-59,60-69,70-79$, and 80-99 years were given by the age distribution of all women with breast cancer included in survival analyses for England and Wales for the period $1986-90 .^{25}$

\section{RESULTS}

Among 115712 women diagnosed during 1986-90, 1010 $(0.9 \%)$ were identified as being of South Asian origin. Visual inspection showed that all these women had at least one South Asian name. Two South Asian names, missed by

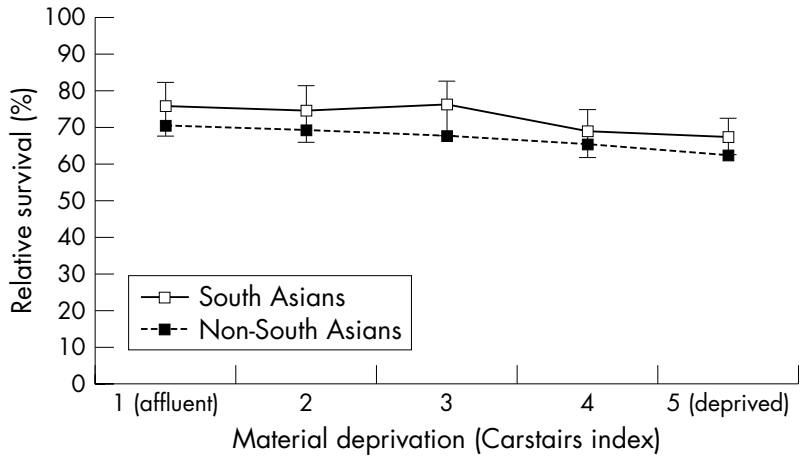

Figure 1 Five year survival (\%) from breast cancer, with 95\% confidence intervals, by material deprivation and ethnic group: England and Wales, women diagnosed 1986-1990.

SANGRA because of unusual variations in spelling, were identified among the 1157 records inspected to check for false negatives. This would suggest that $0.1 \%-0.2 \%$ of women with breast cancer who were identified as non-South Asian might actually be South Asian.

South Asian women were much younger than other women with breast cancer (table 1), with a mean age at diagnosis of 51.8 years (compared with 62.8 years for nonSouth Asians), and 16\% (compared with 5\%) aged under 40 at diagnosis. Crude annual incidence rates were 42.8 per 100000 among South Asian women and 111.2 for other women. Incidence was lower for South Asians in every age group: the world standardised incidence rate ${ }^{33}$ for South Asians (40.5 per 100000 ) was $29 \%$ lower than for other women (57.4).

In South Asian women, five year survival was highest for those aged 60-69 years at diagnosis (74.2\%), while for nonSouth Asian women the highest survival was seen for women aged 40-49 (73.3\%). Overall (all ages) survival was some 3\% higher for South Asian women, both at one year $192.5 \%$ compared with $89.8 \%)$ and at five years $(71.3 \%$ compared with $67.8 \%$ ): the $95 \%$ confidence intervals do not overlap.

Table 1 Incidence per 100000 and relative survival (\%) from breast cancer at one and five years, by age at diagnosis and ethnic group, women diagnosed 1986-90, England and Wales

\begin{tabular}{|c|c|c|c|c|c|c|c|c|c|}
\hline \multirow{2}{*}{$\begin{array}{l}\text { Ethnic group } \\
\text { Age at diagnosis }(y)\end{array}$} & \multirow{2}{*}{$\begin{array}{l}\text { Incidence rate } \\
\text { per } 100000\end{array}$} & \multicolumn{2}{|l|}{ Women } & \multicolumn{3}{|c|}{ One year } & \multicolumn{3}{|c|}{ Five years } \\
\hline & & Number & $\%$ & Deaths & Survival (\%) & $95 \% \mathrm{Cl}$ & Deaths & Surviv & $95 \% \mathrm{Cl}$ \\
\hline \multicolumn{10}{|l|}{ South Asian } \\
\hline $15-39$ & 10.2 & 159 & 15.7 & 17 & 89.3 & 83.3 to 93.2 & 51 & 68.0 & 60.1 to 74.7 \\
\hline $40-49$ & 77.5 & 289 & 28.6 & 13 & 95.7 & 92.5 to 97.5 & 85 & 71.3 & 65.6 to 76.2 \\
\hline $50-59$ & 111.7 & 286 & 28.3 & 22 & 92.8 & 88.9 to 95.3 & 84 & 72.6 & 66.7 to 77.6 \\
\hline $60-69$ & 149.2 & 174 & 17.2 & 16 & 92.0 & 86.4 to 95.4 & 53 & 74.2 & 66.1 to 80.7 \\
\hline $70-79$ & 160.9 & 71 & 7.0 & 8 & 91.5 & 79.7 to 96.6 & 28 & 72.1 & 55.9 to 83.2 \\
\hline $80-99$ & 211.8 & 31 & 3.1 & 13 & 63.0 & 40.0 to 79.3 & 24 & 38.9 & 15.4 to 62.0 \\
\hline Overall & 42.8 & 1010 & 100.0 & 89 & 92.5 & 90.6 to 94.1 & 325 & 71.3 & 68.2 to 74.1 \\
\hline Age standardised* & $\begin{array}{l}40.5 \\
(95 \% \mathrm{Cl} 37.9 \text { to } \\
43.2)\end{array}$ & & & & 89.6 & 86.2 to 93.0 & & 70.3 & 65.2 to 75.4 \\
\hline \multicolumn{10}{|l|}{ Non-South Asian } \\
\hline $15-39$ & 12.9 & 5594 & 4.9 & 343 & 93.9 & 93.3 to 94.5 & 1964 & 65.1 & 63.8 to 66.3 \\
\hline $40-49$ & 102.8 & 16967 & 14.8 & 853 & 95.1 & 94.8 to 95.5 & 4666 & 73.3 & 72.6 to 73.9 \\
\hline $50-59$ & 171.1 & 22235 & 19.4 & 1744 & 92.6 & 92.2 to 92.9 & 7039 & 70.3 & 69.7 to 71.0 \\
\hline $60-69$ & 222.2 & 29294 & 25.5 & 3056 & 90.7 & 90.4 to 91.1 & 10255 & 70.4 & 69.8 to 71.0 \\
\hline 70-79 & 227.2 & 24395 & 21.3 & 4062 & 86.1 & 85.6 to 86.6 & 11546 & 64.9 & 64.1 to 65.6 \\
\hline $80-99$ & 247.6 & 16217 & 14.1 & 5298 & 74.2 & 73.3 to 75.0 & 11921 & 47.4 & 46.2 to 48.6 \\
\hline Overall & 111.2 & 114702 & 100.0 & 15356 & 89.8 & 89.6 to 90.0 & 47391 & 67.8 & 67.5 to 68.1 \\
\hline Age standardised* & $\begin{array}{l}57.4 \\
(95 \% \mathrm{Cl} 57.0 \text { to } \\
57.7)\end{array}$ & & & & 88.8 & 88.6 to 89.0 & & 66.7 & 66.4 to 67.0 \\
\hline
\end{tabular}

*Incidence rates are standardised to the world standard population, and survival rates to the combined age structure of South Asian and non-South Asian women included in the analyses. 
Table 2 Relative survival (\%) from breast cancer at one and five years, by deprivation category and ethnic group, women diagnosed 1986-90, England and Wales

\begin{tabular}{|c|c|c|c|c|c|c|c|c|}
\hline \multirow{2}{*}{$\begin{array}{l}\text { Ethnic group } \\
\text { Deprivation }\end{array}$} & \multicolumn{2}{|l|}{ Women } & \multicolumn{3}{|c|}{ One year } & \multicolumn{3}{|c|}{ Five years } \\
\hline & Number & $\%$ & Deaths & Surviv & $95 \% \mathrm{Cl}$ & Deaths & Surviv & $95 \% \mathrm{Cl}$ \\
\hline \multicolumn{9}{|l|}{ South Asian } \\
\hline 1 (Affluent) & 156 & 15.5 & 9 & 94.9 & 89.7 to 97.6 & 45 & 75.9 & 67.7 to 82.3 \\
\hline 2 & 143 & 14.2 & 12 & 93.4 & 87.2 to 96.7 & 42 & 74.7 & 66.0 to 81.5 \\
\hline 3 & 157 & 15.5 & 10 & 95.3 & 89.8 to 97.8 & 44 & 76.3 & 68.0 to 82.6 \\
\hline 4 & 222 & 22.0 & 22 & 91.3 & 86.5 to 94.4 & 76 & 69.0 & 62.0 to 74.9 \\
\hline 5 (Deprived) & 321 & 31.8 & 36 & 90.2 & 86.1 to 93.2 & 115 & 67.3 & 61.5 to 72.4 \\
\hline 6 (Unknown) & 11 & 1.1 & 0 & - & - & 3 & - & - \\
\hline $\begin{array}{l}\text { Overall } \\
\text { Non-South Asian }\end{array}$ & 1010 & 100.0 & 89 & 92.5 & 90.6 to 94.1 & 325 & 71.3 & 68.2 to 74.1 \\
\hline 1 (Affluent) & 25390 & 22.1 & 2855 & 91.6 & 91.2 to 92.0 & 9482 & 70.6 & 69.9 to 71.2 \\
\hline 2 & 26211 & 22.9 & 3258 & 90.7 & 90.2 to 91.1 & 10392 & 69.2 & 68.5 to 69.8 \\
\hline 3 & 24708 & 21.5 & 3269 & 89.9 & 89.4 to 90.3 & 10219 & 67.8 & 67.1 to 68.5 \\
\hline 4 & 21504 & 18.8 & 3161 & 88.6 & 88.1 to 89.0 & 9469 & 65.5 & 64.7 to 66.2 \\
\hline 5 (Deprived) & 15364 & 13.4 & 2591 & 86.4 & 85.8 to 87.0 & 7221 & 62.4 & 61.5 to 63.3 \\
\hline 6 (Unknown) & 1525 & 1.3 & 222 & - & - & 608 & - & - \\
\hline Overall & 114702 & 100.0 & 15356 & 89.8 & 89.6 to 90.0 & 47391 & 67.8 & 67.5 to 68.1 \\
\hline
\end{tabular}

South Asian women with breast cancer are younger than other women, however: age standardised one year survival was similar in South Asian women (89.6\%) and other women $(88.8 \%)$. Five year age standardised survival in South Asian women $(70.3 \%$, 95\% CI 65.2 to 75.4$)$ was still $3.6 \%$ higher than for non-South Asian women (66.7\%; 66.4 to 67.0), but the confidence intervals overlap.

Deprivation status was known for some $99 \%$ of both ethnic groups. South Asian women were categorised as more deprived: over half $(54 \%)$ lived in areas in the two most deprived quintiles, compared with only a third (32\%) of nonSouth Asians.

Within each deprivation category, South Asian women had higher survival: $2.8 \%-5.4 \%$ higher at one year and $3.5 \%-8.5 \%$ higher at five years (table 2, fig 1), although none of these differences is individually significant. In both ethnic groups, five year survival was $8 \%-9 \%$ higher for affluent women than deprived women.

Breast cancer survival varies with anatomical sub-site and morphological type, but the distribution of both variables was similar in both ethnic groups (data not shown).

\section{DISCUSSION}

This is the first national study of cancer survival among South Asians, the largest ethnic minority in Britain. The survival up to 1995 of South Asian women diagnosed with breast cancer in England and Wales during 1986-90 seems to have been 3\%-4\% higher than for non-South Asian women, and at the very least is not worse.

In the absence of information on self ascribed ethnicity, use of a computer algorithm to assign ethnicity on the basis of the women's names was the only feasible approach, but it is probably subject to some error if the dictionary of names is not complete. SANGRA contains many thousands of South Asian names and has been extensively tested. ${ }^{26}$ It has been shown to recognise South Asian origin in reference datasets with high sensitivity $(89 \%-96 \%)$, specificity $(94 \%-98 \%)$, positive predictive value $(80 \%-89 \%)$, and negative predictive value $(98 \%-99 \%)$.

Validation within this study also suggested acceptable performance. All 1010 women identified by the algorithm did have South Asian names, and only two $(0.17 \%)$ of a sample of 1157 women classified as non-South Asian seemed to have been wrongly classified, suggesting sensitivity of about $99.8 \%$ and specificity $100 \%$. Even so, because of the very large number of women included in the study, even this degree of sensitivity would imply that some 200 South Asian women could have been missed, representing up to $17 \%$ (200 of 1210 ) of the total who should have been so categorised. A very much larger validation sample would have been required to estimate misclassification of ethnicity more accurately. There is no reason to expect, however, that South Asian women whose names were not recognised by SANGRA would have systematically different survival from those with names it did recognise, so survival estimates for women identified as South Asian are unlikely to be subject to bias from this source.

Life tables were not available for each ethnic group. All cause mortality in South Asian women over the age range 2069 years was the same as the national average for England and Wales during 1989-92 (SMR $=100)$, however, ${ }^{33}$ and the national life tables we used to estimate relative survival, which reflect background mortality during 1990-92 for all ethnic groups combined, are therefore likely to be perfectly adequate for South Asian women.

The validity of the Carstairs index as a measure of material deprivation in South Asians is unclear. Inclusion of "household over-crowding" (more than one person per habitable room) may lead to bias in the assessment of deprivation in

\section{Policy implications}

- This is the first national study of cancer survival in any ethnic group in England and Wales. South Asians are the largest ethnic minority $(2.7 \%)$. It suggests that breast cancer survival in South Asian women is higher than in non-South Asian women, both overall and in each category of deprivation.

- This surprising finding represents an important baseline for surveillance of cancer survival in South Asians. Data on cancer incidence, survival, and mortality in ethnic minorities are vital for addressing their specific public health concerns, but such data remain sparse in the UK. Surveillance of screening compliance, stage at diagnosis, and equality of access to treatment is also required.

- Making information on cancer in ethnic minority populations routinely available will require systematic recording of ethnicity at hospital admission, cancer registration, and certification of death. 
census enumeration districts with large numbers of South Asians, who tend to live together with more members of the extended family. "Over-crowding" in these districts would not necessarily indicate deprivation to the same degree as in other enumeration districts. The effect of any bias is likely to be attenuated, however, because over-crowding is only one of the four components of the Carstairs index.

Breast cancer incidence in South Asian women was lower than for other women in every age group, and age standardised incidence was some 30\% lower. Survival varied considerably with age in both populations. Age standardised five year survival was slightly higher in South Asians than other women. Five year survival was $8 \%-9 \%$ higher for both South Asian and other women in affluent areas than for those in deprived areas, the same pattern seen for all women in England and Wales. ${ }^{25}$

One year and five year survival rates were consistently higher in South Asians in each deprivation category. None of the ethnic differences in survival for a given socioeconomic group was conventionally significant, but the consistency is striking. It is unlikely to be an artefact, as mortality from breast cancer in the age range 20-69 years during 1989-92 was significantly lower in South Asian women than other women in England and Wales (SMR $=59,95 \%$ CI 52 to 66). ${ }^{33}$ The corroboration is important, ${ }^{34}{ }^{35}$ because the data streams that generate cancer mortality and cancer survival statistics are independent.

Ethnic differences in breast cancer survival in England and Wales could be partly attributable to differences in stage distribution, but information on stage is not available in the National Cancer Registry for patients diagnosed before 1993. South Asian women with breast cancer were more deprived than other women, and deprived groups generally have more advanced disease at diagnosis. ${ }^{7}$ This would be expected to reduce the observed difference in survival between the two ethnic groups. Differences in breast cancer survival between South Asian and other women in south east England were not explained by differences in stage at diagnosis. ${ }^{36}$

South Asians in Britain are a heterogeneous group with respect to diet and lifestyle, but these differences would be expected to influence the risk of developing cancer rather than the probability of surviving it. ${ }^{37}$ In principle, higher compliance with breast screening among South Asian women could contribute to the observed difference in survival. Compliance seems to be lower among South Asian women than other women, however, and the differences are small after socioeconomic deprivation is taken into account. ${ }^{38}$ Less than a third of all breast cancers occur in the screening age range $50-64$ years. ${ }^{39}$

Most ethnic minorities in the USA have systematically lower cancer survival rates than the white majority. ${ }^{40}$ African American women diagnosed with breast cancer in the USA during 1986-96 had later stage at diagnosis and poorer survival than white women. ${ }^{41}$ These differences were partially explained by adjustment for socioeconomic variables, which may reflect variations in access to and use of healthcare services. Clinical trials have shown that black and white women diagnosed at a comparable stage and treated appropriately have similar survival..$^{42}$ Such results provide evidence that equal treatment yields equal outcome, regardless of race. ${ }^{40}$ The evidence suggests, however, that black people in the USA tend to receive less aggressive investigation or less appropriate treatments than white people, both for cancer and other diseases. ${ }^{43} 44$

Asian Americans are an interesting exception to the pattern of lower survival in minority racial/ethnic groups in the USA. Age and stage adjusted five year survival for women diagnosed with breast cancer during 1988-97 and followed up to 1988 in the SEER programme areas was slightly higher for Asian Americans than for other racial groups. ${ }^{45}$ As in our data, socioeconomic gradients in breast cancer survival were seen among both Asian and other ethnic groups across three categories defined by median census tract income for women diagnosed 1988-1994. ${ }^{17}$ South Asians in England and Wales are persons with an origin in the Indian subcontinent (India, Pakistan, Bangladesh) whereas in the USA, Asian Americans are persons of Chinese, Japanese, or Filipino origin. The finding that breast cancer survival is higher among Asian women than other women in both countries is thus all the more surprising. It is difficult to explain on the basis of chance, artefact, or the choice of life tables. Confounding by stage of disease, socioeconomic status, or healthcare access cannot be excluded, but would be expected to confer lower survival on South Asians in the UK. We can speculate that differential access to (or compliance with) treatment or differences in tumour biology, or both, may contribute to the differences in survival.

Asian Americans also had higher survival than other ethnic groups in the USA for prostate cancer and for colorectal cancer in both sexes, ${ }^{45}$ and it would be interesting to examine survival for other cancers in British Asians.

Data on cancer incidence, survival, and mortality are vital to address the public heath concerns of ethnic minorities, but such data remain sparse in the UK. Better health surveillance is required for these communities, as in the USA ${ }^{46}$ including incidence, compliance with screening, stage at diagnosis, access to treatment, survival, and mortality.

\section{ACKNOWLEDGEMENTS}

We are grateful to Dr Isabel dos Santos Silva for her help with SANGRA.

\section{Authors' affiliations}

S Farooq, M P Coleman, Non-communicable Disease Epidemiology Unit, London School of Hygiene and Tropical Medicine, London, UK

Funding: none.

Conflicts of interest: none declared.

\section{REFERENCES}

1 Coleman MP, Estève J, Damiecki P, et al. Trends in cancer incidence and mortality (IARC Scientific Publications no 121). Lyon: International Agency for Research on Cancer, 1993.

2 Parkin DM, Whelan SL, Ferlay J, et al. Cancer incidence in five continents, volume VIII (IARC Scientific Publications no 155). Lyon: International Agency for Research on Cancer, 2002.

3 Gatta G, Capocaccia R, Coleman MP, et al. Toward a comparison of survival in American and European cancer patients. Cancer 2000;89:893-900.

4 Coleman MP, Gatta G, Verdecchia A, et al. EUROCARE-3 summary: cancer survival in Europe at the end of the 20th century. Ann Oncol 2003;14:v128-49.

5 Carnon AG, Lamont DW, Hole DJ, et al. Survival from breast cancer, stage at presentation and socioeconomic deprivation. J Epidemiol Community Health 1993;47:400.

6 Richardson JL, Langholz B, Bernstein L, et al. Stage and delay in breast cancer diagnosis by race, socio-economic status, age and year. $\mathrm{Br} J$ Cancer 1992;65:922-6.

7 Schrijivers CTM, Mackenbach JP, Lutz J-M, et al. Deprivation and survival from breast cancer. $\mathrm{Br} J$ Cancer 1995;72:738-43

8 Vernon SW, Tilley BC, Neale AV, et al. Ethnicity, survival, and delay in seeking treatment for symptoms of breast cancer. Cancer 1985;55:1563-71.

9 Karjalainen S, Pukkala E. Social class as a prognostic factor in breast cancer survival. Cancer 1990;66:819-26.

10 Dignam JJ, Colangelo L, Tian W, et al. Outcomes among African-Americans and Caucasians in colon cancer adjuvant therapy trials: findings from the national surgical adjuvant breast and bowel project. J Natl Cancer Inst 1999:91:1933-940.

11 Sant M, Capocaccia R, Coleman MP, et al. Cancer survival increases in Europe, but international differences remain wide. Eur $J$ Cancer 2001;37:1659-67.

12 Lannin DR, Mathews HF, Mitchell J, et al. Influence of socioeconomic and cultural factors on racial differences in late-stage presentation of breast cancer. JAMA 1998;279:1801-7.

13 Ansell D, Whitman S, Lipton R, et al. Race, income, and survival from breast cancer at two public hospitals. Cancer 1993;72:2974-8. 
14 Basseft MT, Kreiger N. Social class and black-white differences in breast cancer survival. Am J Publ Hlth 1986;76:1400-3.

15 Dayal HH, Power RN, Chiu C. Race and socio-economic status in survival from breast cancer. J Chron Dis 1982;35:675-83.

16 Gordon NH, Crowe JP, Brumberg DJ, et al. Socioeconomic factors and race in breast cancer recurrence and survival. Am J Epidemiol 1992;135:609-18.

17 Singh GK, Miller BA, Hankey BF, et al. Area socio-economic variations in US cancer incidence, mortality, stage, treatment, and survival, 1975-1999. NCl Cancer Surveillance Monograph Series, Number 4. NIH Publication no 035417. Bethesda, MD: National Cancer Institute, 2004.

18 Office of Population Censuses and Surveys. 1991 Census: ethnic group and country of birth. Great Britain. Vol 2. London: HMSO, 1993.

19 Barker RM, Baker MR. Incidence of cancer in Bradford Asians. J Epidemiol Community Health 1990:44:125-9.

20 Winter H, Cheng KK, Cummins $\mathrm{C}$, et al. Cancer incidence in the south Asian population of England (1990-92). Br J Cancer 1999;79:645-54.

21 Smith LK, Botha JL, Benghiat $A$, et al. Latest trends in cancer incidence among UK South Asians in Leicester. Br J Cancer 2003;89:70-3.

22 Coleman MP, Babb P, Mayer D, et al. Cancer survival trends in England and Wales 1971-1995: deprivation and NHS region (CD ROM). London: Office for National Statistics, 1999

23 Carstairs V. Deprivation indices: their interpretation and use in relation to health. J Epidemiol Community Health 1995;49:s3-8.

24 Carstairs V. Morris R. Deprivation and health in Scotland. Aberdeen: Aberdeen University Press, 1991.

25 Coleman MP, Babb P, Damiecki P, et al. Cancer survival trends in England and Wales 1971-1995: deprivation and NHS region. Series SMPS no 61. London: The Stationery Office, 1999.

26 Nanchahal K, Mangtani P, Alston M, et al. Development and validation of a computerized South Asian names and group recognition algorithm (SANGRA) for use in British health-related studies. J Public Health Med 2001;23:278-85.

27 Berkson J, Gage RP. Calculation of survival rates for cancer. Proc Staff Meet Mayo Clinic 1950;25:270-86.

28 Cutler SJ, Ederer F. Maximum utilisation of the life table method in analyzing survival. J Chron Dis 1958;8:699-712.

29 Ederer F, Axtell LM, Cutler SJ. The relative survival: a statistical methodology. Natl Cancer Inst Monogr 1961;6:101-21.

30 Estève J, Benhamou $E$, Croasdale $M$, et al. Relative survival and the estimation of net survival: elements for further discussion. Stat Med 1990;9:529-38.

31 Office of Population Censuses and Surveys. English life tables no 151990 1992. Series DS no 14. London: HMSO, 1997.
32 Smith PG. Comparison between registries: age-standardized rates. In: Parkin DM, Muir CS, Whelan SL, et al. Cancer incidence in five continents. Vol 5. (IARC Scientific Publications no 120). Lyon: International Agency for Research on Cancer, 1992:865-70.

33 Wild S, McKeigue P. Cross-sectional analysis of mortality by country of birth in England and Wales, 1970-92. BMJ 1997;314:705-10.

34 Peto R, Boreham J, Clarke M, et al. UK and USA breast cancer deaths down $25 \%$ in year 2000 at ages $20-69$ years. Lancet 2000;355:1822.

35 Coleman MP, Babb P, Stockton DL, et al. Breast cancer incidence, survival and mortality trends in England and Wales (Erratum in Lancet 2000;356:774). Lancet 2000;356:590-1.

36 dos Santos Silva I, Mangtani P, De Stavola BL, et al. Survival from breas cancer among South Asian and non-South Asian women resident in South East England. Br J Cancer 2003;89:508-12.

37 McCormack VA, Mangtani P, Bhakta D, et al. Heterogeneity of breast cancer risk within the South Asian female population in England: a population-based case-control study of first-generation migrants. $\mathrm{Br} J$ Cancer 2004;90:160-6.

38 Hoare T. Breast screening and ethnic minorities. Br J Cancer 1996;74:S38-41.

39 Office of Population Censuses and Surveys. Cancer statistics, registrations: England and Wales, 1989. Series MB1 no 22. London: HMSO, 1994.

40 Brawley OW, Freeman HP. Race and outcomes: is this the end of the beginning for minority health research? J Natl Cancer Inst 1999;91:1908-9.

41 Yood MU, Johnson CC, Blount A, et al. Race and differences in breast cancer survival in a managed care population. J Natl Cancer Inst 1999;91:1487-91.

42 Dignam JJ. Differences in breast cancer prognosis among African-American and Caucasian women. CA Cancer J Clin 2000;50:50-64.

43 Breen N, Wesley MN, Merrill RM, et al. The relationship of socio-economic status and access to minimum expected therapy among female breast cancer patients in the National Cancer Institute black-white cancer survival study. Ethn Dis 1999;9:111-25.

44 McKinlay JB, Burns RB, Durante R, et al. Patient, physician and presentational influences on clinical decision making for breast cancer: results from a factorial experiment. J Eval Clin Pract 1997;3:23-57.

45 Clegg LX, Li FP, Hankey BF, et al. Cancer survival among US whites and minorities: a SEER (surveillance, epidemiology and end results) Program population-based study. Arch Intern Med 2002;162:1985-93.

46 National Cancer Institute. Racial/Ethnic Patterns of Cancer in the United States, 1988-1992. National Cancer Institute 2002. hitp://seer.cancer.gov/ publications/ethnicity/ (Accessed 5 Aug 2002). 